\title{
XXXIV. Observations on shooting stars on the nights of the 9th, 10th, and 11th of August 1838
}

\section{Quetelet \& E.J. Cooper Esq. M.P.}

To cite this article: M. Quetelet \& E.J. Cooper Esq. M.P. (1838) XXXIV. Observations on shooting stars on the nights of the 9th, 10th, and 11th of August 1838, Philosophical Magazine Series 3, 13:82, 252-256, DOI: $10.1080 / 14786443808649569$

To link to this article: http://dx.doi.org/10.1080/14786443808649569

册 Published online: 01 Jun 2009.

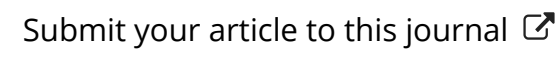

Џll Article views: 1

Q View related articles $\widetilde{ }$ 
impossible to keep oxygen, nitrogen, or any other gas in its original purity, if confined by water. This fluid, which when reduced to a thin imperceptible film is instantaneously permeated by almost every substance, undergoes the like action in course of time, even in deep masses. Gases are absorbed by it, and thrown off by it, in its purest state; how much more complicated then must its action be in that impure condition in which it is commonly used! Connected with this point, there is another: if a series of bells stand on a pneumatic trough, each will affect all the others, communicating a part of its contents and receiving from them in return. A jar containing binoxide of nitrogen, standing by the side of one containing common air, seriously affects it. I have noticed that two common tumblers, filled with these gases and so placed, communicate with each other, and so freely, that in 17 hours the tumbler originally filled with atmospheric air contained only $9 \frac{3}{4}$ per cent. of oxygen. The habit of collecting gases at the same trough that is destined to preserve others is very exceptionable: we place the disturbing agency in circumstances the most favourable for its action. All operations of washing are liable to the same strictures."

I fear I have intruded upon you too long a letter. I have been encouraged to do so; for we are accustomed in America to associate with your name whatever there is of exactitude in chemistry. In gaseous mechanics the most important observations are due to your labours; and anything that may have even a remote bearing on the subject, will, I am persuaded, meet with acceptance from you.

Your obedient servant,

John W. Draper.

XXXIV. Observations on Shooting Stars on the Nights of the 9th, 10th, and 11th of August 1838. By M. QueTELET, Director of the Observatory of Brussels, \&c. \&c. \&c., and by E. J. Cooper, Esq. M.P.*

\section{To Richard Taylor, Esq. Editor of the Philosophical Magazine.}

DenR Sir,

I RECEIVED the letter of which the following is an extract the day after the last meeting of the Physical Section of the British Association at Newcastle, and was therefore not able to comply with the request of M. Quetelet to present the interesting particulars which it contains to the notice of the Section. It seems to me that it I shall equally well effect

- See Lond. and Edinb. Phil. Mag., vol, xi. p. 261. 
on the nights of the $9 \mathrm{th}, 10 \mathrm{th}$, and 11 th of August. 253

M. Quetelet's objects by calling attention to his observations in your Journal, and by requesting that if any similar ones have been made in Great Britain, they may be communicated to you.

London, Aug. 30, 1838.

Very respectfully yours,

\author{
A. D. BACHE, \\ President of the Gir. Coll. \\ Philadelphia.
}

Extract of a Letter from M. Quetelet, Director of the Observatory of Brussels, to Prof. A. D. Bache, of Philadelphia.

"I observed the number of shooting stars visible here (at Brussels) on the nights of the 9th, 10th, and 11 th of August. On the first of these nights the sky was almost entirely covered with clouds, and I saw but two shooting stars.

" On the night of the 11 th, until nearly midnight, about one third of the sky towards the zenith was generally clear. Subsequently it was only clear at intervals, and towards two o'clock it rained. I was assisted in my observations by two other persons; and notwithstanding the unfavourable circumstances of the night we saw many shooting stars, besides several very brilliant meteors, with nearly all of them a luminous train. The uniform direction of their motion was further remarkable. Below is the result of our observations on the night of the 10th, giving the directions of the paths of the shooting stars and the hours between which the numbers given were seen.

49 directed from between the north and east towards the opposite quarter of the sky.

1 between the south and west towards the opposite quarter of the sky.

4. between the south and east towards the opposite quarter of the sky.

11 between the north and west towards the opposite quarter of the sky.

5 from east to west.

1 from west to east.

4 from north to south.

1 from south to north.

76

11 not well determined.

87 total number seen.

Of these were seen :

16 between $9-10$ o'clock. The observations ahout 9 o'clock were interrupted for about1 5 minutes by clouds. 


\section{Mr. E, J. Cooper's Observations on Shooting Stars}

29 between 10-11 o'clock.

39 between 11, and 11 and 50 minutes. The sky then clouded over.

3 after midnight in the clear intervals.

"I estimate at double the number just given what we should probably have seen had the weather been favourable.

"On the night of the 11th the sky was clear until towards two o'clock. At half past two it was covered with clouds. I had on this occasion three assistants. We saw

2 shooting stars before 9 o'clock.

34. between 9-10 o'clock.

19 between 10-11,

24 between $11-12$,

32 between $12-1$,

12 between 1-2,

10 between $2-3$ "

2 after 3 o'clock.

135 total number of shooting stars which were seen. The directions of the motions were

71 from between the north and east towards the opposite part of the sky.

3 between the south and west towards the opposite part of the sky.

16 between the south and east towards the opposite part of the sky.

10 between the north and west towards the opposite part of the sky.

10 from east to west.

2 from west to east.

13 from north to south.

6 from south to north.

131, leaving four, the directions of which were not well determined.

"The shooting stars of the 11 th, though fine, were less so than those of the 10th. The general direction, as has been seen, was from the north-east towards the south-west."

[The following notice on the same subject has been communicated by the Rev. T. R. Robinson, D.D. of Armagh.]

Extract of a Letter from Edward J. Cooper, Esq., M.P.

“My dear Dr. Robinson, Geneva, Aug. 15, 1838.

"I have not been able to do much in arranging the observations made of falling stars on the nights 10-11 instant, as I only received those made by my companions last night. 
on the nights of the 9 th, 10th, and 11 th of August. 255

The total number seen from $8^{\mathrm{h}}$ to $16^{\mathrm{h}}$ was upwards of 380 . The number actually abserved $=373$, of which 123 fell to my list. My companions were M. Wartman and his two sons, M. Müller of the Observatory, and M. Borel, a friend of his. At $8^{\mathrm{h}}$ two banks of clouds converged to a point on the horizon N. $40 \mathrm{E}$. This point moved subsequently about $5^{\circ}$ more to the E. ; and at $9^{\mathrm{h}} 45^{\mathrm{m}}$ the clouds had become much darker, and the angle of convergence had greatly increased. At $10^{\text {h }}$ they had become white and thin, and nearly concealed the north from the horizon to $\alpha$ Lyræ. About 14, they had moved northward, and the point of convergence was at N. $35 \mathrm{E}$. Heavy dew, night perfectly calm. Three of the stars passed apparently over clouds. I can now merely class my own observations as follows. I find I am too late for post today, so will endeavour to class the total. Aug. 16th. I have found that it requires a very long time, so I can only give you the total numbers from and to each constellation. I shall place the number from before, and the number to atter, the name of the constellation. I have not time to check my work.

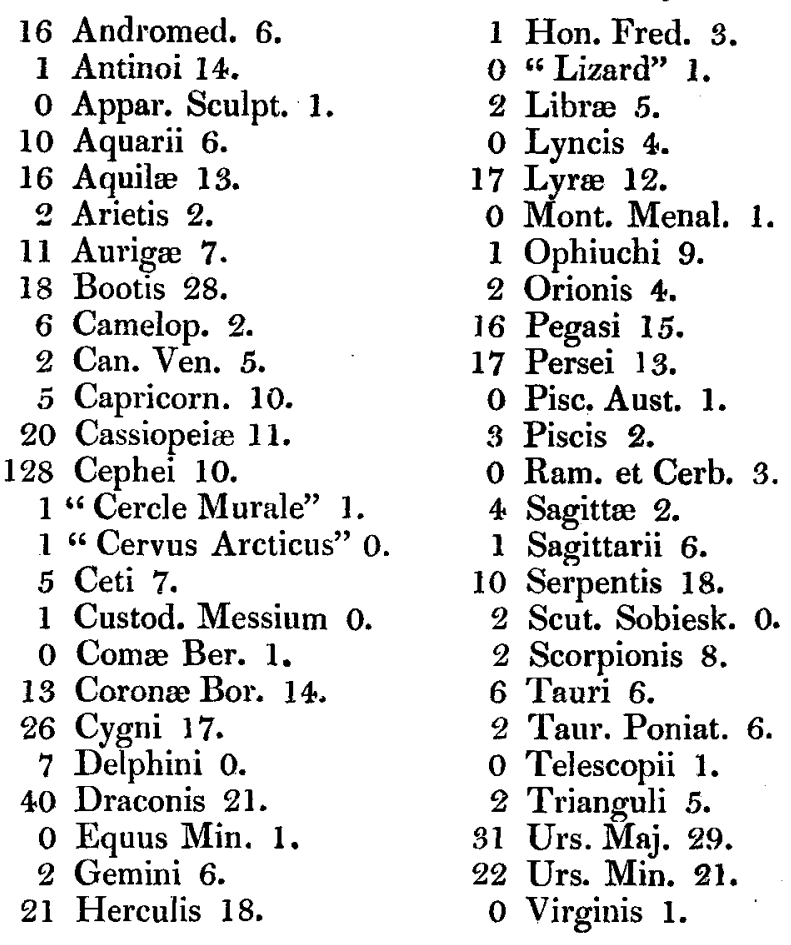

"You will perceive that the numbers here particularized do 
not accord with the grand total, nor can I, as I have already said, check them. I think however that there is enough to prove that on the 10th of August at least there has been nothing to support the idea of a common focus. I also must add, that on the following night there were only 3 per hour less in number."

\section{Conjectures on the Cause of the peculiar Condition of Iron. By Dr. Schonhein.**}

SEVERAL attempts have already been made to explain

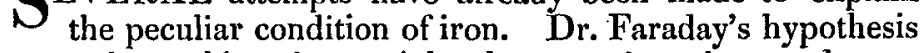
upon that subject is certainly the most ingenious and most plausible of all the theories as yet brought forward, but there are some facts pointed out by me elsewhere, which do not well agree with the views of that distinguished philosopher. As the matter alluded to is of some importance with respect to electrical science, and all the theories hitherto announced upon the cause of the anomalous relations of the iron having failed, I may, perhaps, be allowed to suggest some ideas regarding the delicate point in question. But before doing it I must not omit to say, that I do not lay much stress upon my conjectures, and that I have only ventured to make them public, because I hope they will engage some philosopher more able than myself to take up the subject, and clear up by new investigations the darkness which still invests the cause of the inactivity of iron.

Chemistry in our days accounts for the difference of qualities exhibited by what are called "isomeric bodies" by asserting that the same number of particles of the same elements are capable of grouping themselves in different ways. Now if heterogeneous atoms be capable of combining in various manners, is it not possible that homogeneous ones may do the same, and in such a way as to give rise to substances essentially distinct from each other not only with regard to their physical, but also as to their chemical properties? Sulphur, selenium, phosphorus, and carbon prove indeed that simple substances are capable of assuming states almost as different from each other as any two isomeric bodies are in qualities. It is true, the difference of properties which we sometimes observe in the same element is generally referable to a modification of the cohesive attraction of its molecules brought about by the agency of heat; but $I$ am almost sure,

- Communicated by Mr. Faraday, to whom it had been addressed by the Author. 